\title{
Ethnogenèse du New Age andin : à la recherche de l'Inca global
}

Antoinette Molinié

\section{(2) OpenEdition}

Journals

Édition électronique

URL : https://journals.openedition.org/jsa/12192

DOI : 10.4000/jsa. 12192

ISSN : $1957-7842$

Éditeur

Société des américanistes

Édition imprimée

Date de publication : 31 juillet 2012

Pagination : 171-199

ISSN : 0037-9174

Référence électronique

Antoinette Molinié, «Ethnogenèse du New Age andin : à la recherche de l'Inca global », Journal de la Société des américanistes [En ligne], 98-1 | 2012, mis en ligne le 10 mai 2015, consulté le 02 septembre 2022. URL : http://journals.openedition.org/jsa/12192 ; DOI : https://doi.org/10.4000/jsa. 12192 


\title{
POSITION
}

\section{ETHNOGENÈSE DU NEW AGE ANDIN : À LA RECHERCHE DE L'INCA GLOBAL}

\author{
Antoinette MOLINIÉ *
}

\begin{abstract}
Nous observons au Pérou l'émergence d'une culture originale à partir de deux corpus : celui des Andins, fruit d'un alliage entre la culture préhispanique et le christianisme, et celui du mouvement New Age introduit par le tourisme mystique. La fusion de ces deux matrices donne lieu à des créations rituelles qui sont ici décrites et analysées. À travers un travail ethnographique, nous avons identifié des procédés d'invention de cette nouvelle tradition. Les néo-Incas ont donné une dimension préhispanique impériale à quelques cultes indigènes. L'Indien étatique a servi de figure d'autochtonie à la nation péruvienne. Les New Agers ont repris ces représentations néo-indiennes sur lesquelles ils ont greffé leurs concepts. La mondialisation d'une tradition est ainsi présentée non pas au travers de débats théoriques sur la globalisation des cultures, mais par l'analyse de données ethnographiques. [Mots-clés : Andes, Pérou, rituel, New Age, invention de la tradition, néo-Inca.]
\end{abstract}

Ethnogenesis of the Andean New Age : in search of the global Inca. In Peru, we witness the emergence of an original culture that takes its roots from two matrices : the Andean culture that results from a fusion of the pre-Hispanic culture with Christianism, and the New Age movement that has been introduced with mystic tourism. The fusion of these two strands gives rise to ritual creations that we describe and analyze. Through ethnographical observations, we have identified some of the inventive procedures of this new tradition. The neo-Incas have given an imperial pre-Hispanic dimension to indigenous cults. The State Indian has offered a model of autochtony to the Peruvian nation. The New Agers movement have borrowed from neo-Indian representations and grafted their own concepts on them. In this manner, the world-wide popularization of a tradition is not introduced through some theoretical debate on the way cultures tend

* CNRS/université Paris Ouest Nanterre La Défense, UMR 7186, Maison Archéologie et Ethnologie, 21 allée de l'université, 92023 Nanterre [antoinette.molinie@mae.u-paris10.fr].

Journal de la Société des Américanistes, 2012, 98-1, pp. 171-199. (C) Société des Américanistes. 
to dissolve in globalization, but through the analysis of ethnographic data. [Key words : Andes, Peru, ritual, New Age, invention of tradition, neo-Inca.]

Etnogénesis del New Age andino : en busca del inca global. En Perú observamos el brote de una cultura original a partir de dos cuerpos : el de lo andino, resultado de una aleación entre la cultura prehispánica y el cristianismo, y el del movimiento New Age introducido por el turismo místico. La fusión de estas dos matrices produce creaciones rituales que describimos y analizamos. Por medio de un trabajo etnográfico, hemos podido identificar algunos procedimientos de invención de esta nueva tradición. Los neo-incas han dado una dimensión prehispánica imperial a cultos indígenas. El indio estatal ha proporcionado una figura de autoctonía a la nación peruana. Los new agers han recogido estas representaciones neo-indias a las que han injertado sus conceptos. Presentamos así la mundialización de una tradición no en forma de debate teórico sobre la globalización de las culturas, sino a través del análisis de datos etnográficos. [Palabras claves : Andes, Perú, ritual, New Age, invención de la tradición, neo-inca.]

Une tradition andine veut qu'Inkarrí, le souverain de l'empire inca, revienne un jour au Pérou pour restaurer le peuple indien. De sa tête enterrée quelque part dans la cordillère, son corps croît peu à peu et, quand il sera complet, Inkarrí se redressera et prendra le pouvoir ${ }^{1}$. Certains rapportent comment Inkarrí a vaincu son frère Jésus-Christ, appelé Sucristu ou Españarri selon les versions. Ce dernier a caché la tête du roi inca, mais

[...] Le sang d'Inkarrí vit au fond de la Terre Mère. On affirme qu'il reviendra le jour où sa tête, son sang et son corps s'uniront. Ce jour se lèvera au crépuscule, les reptiles voleront. Le lac de Parinacochas s'asséchera, alors le beau et grand peuple que notre Inkarrí n'a pas pu terminer sera de nouveau visible ${ }^{2}$.

Depuis une dizaine d'années, ce sont des milliers d'adeptes du New Age ${ }^{3}$ qui, des États-Unis au Tibet, attendent le retour de l'Inca. Cette légende locale est devenue la doxa globale d'un New Age andin dont on peut aujourd'hui étudier l'invention. Nous assistons en effet à la genèse d'une culture à partir de deux corpus : d'une part, les croyances andines dites " traditionnelles », héritage de cinq siècles d'alliage entre les cultures préhispaniques et espagnoles, d'autre part, le mouvement du New Age qui est introduit au Pérou essentiellement par le biais du tourisme mystique. On voit alors s'élaborer un métissage entre ce courant et la culture andine traditionnelle comparable à celui qui s'est produit entre la religion préhispanique et le christianisme. De la même manière que celui-ci a accommodé des croyances et des rites andins à ses dogmes, le New Age trouve dans la pensée andine des concepts et des pratiques qu'il assimile tout en les transformant. C'est à la construction de cette nouvelle culture, à la fois andine et new age, que nous nous intéresserons ${ }^{4}$. 


\section{L'APPROPRIATION D'UNE TRADITION : QUELQUES CONCEPTS ANDINS PROCHES DU New Age}

De nombreuses prophéties new age annoncent que l'entrée dans l'ère du verseau $^{5}$ s'accompagnera de bouleversements profonds décrits dans l'Apocalypse de saint Jean. Un cataclysme amènera un « Grand Roi » dont l'avènement apparaîtra comme un retour du Christ et initiera un nouvel Âge d'Or. On voit bien ce qui rapproche cette croyance de celle du retour de l'Inca qui devrait " retourner le monde» pour réinstaurer le Tawantinsuyu, soit l'empire inca conçu comme un paradis. Les deux visions de l'histoire, andine et new age, sont curieusement proches. Le quechua exprime par la notion de pacha à la fois le temps et l'espace. Pour les Andins, l'histoire n'est point linéaire comme la nôtre, mais constituée de différents pacha, des univers séparés par des pachacuti, c'està-dire des renversements (cuti) qui se manifestent par de grandes catastrophes ${ }^{6}$. Cette notion de pachacuti est proche des représentations new age. Les Enfants du Verseau ${ }^{7}$ ont en effet une vision cyclique du devenir comparable à celle des Andins, même si cette dernière est plus complexe. Pour eux, chaque cycle comprend quatre âges successifs, d'or, d'argent, d'airain et de fer. Depuis 2000, un âge d'or s'ouvre devant nous pour 2160 ans, l'humanité serait donc à la charnière d'une ère nouvelle. Tout comme le temps des New Agers, celui des Andins fonctionne de manière cyclique et le pachacuti exprime « dans le mouvement de l'histoire une alternance d'époques charnières correspondant à des changements de rythme, marqués par des bouleversements radicaux » (Vernette 1992, p. 26).

D'autres concepts andins sont également proches de certaines notions du New Age. Par exemple, celui de yanantin exprime, pour les Quechuas l'opposition d'éléments contraires, par ailleurs complémentaires, dont le déséquilibre permanent est en perpétuel ajustement. Il s'agit d'une " relation de symétrie en miroir » (Platt 1978, p. 1098), et le mot s'emploie pour les organes qui vont par paires (comme les yeux) et, singulièrement, pour le couple homme-femme. Cette notion trouve un écho dans celles de yin et de yang dans son acception new age, soit un idéal de complémentarité, appliqué aussi bien aux deux sexes qu'aux couleurs ou aux tempéraments. Les New Agers observent ce principe dans l'ayni andin. À l'origine, ce mot désignait en quechua une prestation de travail mutuelle; aujourd'hui il exprime en milieu urbain toute manifestation de réciprocité, qu'il s'agisse de services rendus, de cadeaux ou d'invitations. Selon les New Agers, la société andine idéale appliquerait la réciprocité dans tous les domaines, dès lors qu'elle n'a pas été polluée par l'idéologie mercantile. Elle aurait atteint par elle-même un idéal du New Age.

Ainsi les notions très locales de pachacuti et de yanantin, une fois simplifiées et dégagées de leur contexte par les exégèses, viennent prendre place tout naturellement dans la vision new age mondialisée. Ce lien entre les deux cultures a reçu la 
caution scientifique d'un anthropologue de l'université de Cuzco qui, dès 1991, identifiait une "Église andine » composée d'un véritable clergé hiérarchisé en grades de «chamanes » (Núñez del Prado J. 1991). On connaît la fortune de ce terme chez les New Agers. De plus en plus, leurs écrits ${ }^{8}$ se présentent comme des travaux d'anthropologie, tandis qu'à l'inverse les études ethnologiques sont « tirées » vers le mysticisme. Les frontières entre les données ethnographiques recueillies sur le terrain et les concepts du New Age tendent à devenir floues. De plus, les néo-chamanes utilisent, dans leurs discours ou dans leurs pratiques, les écrits des anthropologues et des historiens. Au cours de ses enquêtes de terrain, l'ethnologue récolte aujourd'hui ce qu'il pourrait prendre pour des « données ethnographiques » de première main. Mais il constate souvent que celles-ci proviennent de ses propres écrits académiques. Les publications d'histoire ou d'anthropologie sont ainsi recyclées dans des discours apparaissant comme indigènes. Nous verrons, par exemple, comment le calendrier inca établi par Zuidema $(1964,2010)$ en système de ceques connaît une fortune surprenante.

Par ailleurs, la notion new age d' " énergie » rencontre, dans les Andes, des idées complexes et mal connues, mais transposables et même traduites en quechua en des termes comme sami pour l'« énergie raffinée », huaca pour l'« énergie sacrée », hucha pour l'« énergie pesante », poq'po pour la «bulle » d'énergie et kausay pour l'" énergie suspendue dans le monde». On voit comment ce seul et même terme new age d' "énergie » exprime, suivi d'un qualificatif, des notions andines particulièrement variées et hétérogènes. La globalisation procède ainsi par homogénéisation et réduction de concepts indigènes. Pour " manger et digérer l'énergie pesante ", on a recours à son qosqo, soit son plexus solaire, notion essentielle du New Age et inconnue des Indiens des communautés. Il s'agit d'une sorte d'estomac spirituel qui nous permet de digérer l'énergie pesante dégagée par certaines personnes qui génèrent des « vibrations » négatives. Chacun doit apprendre à trouver son qosqo, et pratiquer des techniques appropriées de concentration pour " digérer », grâce à lui, les flux négatifs.

Notons que, depuis 1990, la ville de Cuzco porte le nom de Qosqo ${ }^{9}$, le maire de l'époque ayant décidé que c'était bien le nom préhispanique de la capitale du Tawantinsuyu. Ce baptême fut inspiré par le recours au passé impérial et par le souci d' " authenticité » caractéristique du néo-incaïsme ${ }^{10}$. Qosqo a désormais un drapeau aux couleurs de l'arc-en-ciel (kuychi) qui était une divinité importante du panthéon inca. Aujourd'hui il flotte sur le palais présidentiel à Lima auprès de son équivalent national. Ce dédoublement du drapeau péruvien correspond bien au rôle d'autochtonie attribué à l'iconographie inca dans la fondation de la nation. Cuzco s'est vu attribuer un blason aux motifs de style tiahuanaco, une erreur regrettable reproduite jusque dans les boutiques de souvenirs. Dotée d'un drapeau et d'un blason, Qosqo ne manquait plus que d'un hymne. L'accord municipal 17 du 11 juin 1984 a officialisé celui qu'avaient créé en 1944 le poète cuzquénien Luis Nieto et Roberto Ojeda Campana: 
Qosqo, Qosqo willkasqan sutynki

Inkapachaq Tayta Intin hina

Teqsimunun ahasqonpi apasunki

Haylli taki unanchanta hina

Mana llallin sanankia pukaran

Llaqtakunan much'ankusunki

Sunutaqmi ayllunkiwan samisqa

Mat'inkiman pilluta churan ${ }^{11}$
Cuzco, Cuzco est ton nom sacré

Comme le Soleil de l'immortel empire

Tous te portent dans leur cœur

Tel un chant et un drapeau triomphal.

Bastion invincible de ta race

Les peuples debout te saluent

La Patrie dont ta lignée est l'honneur

Pose un laurier sur ton front.

Cette ode à l'incaïtude prend clairement une valeur nationale. Son texte a été certifié conforme par l'Académie supérieure de la langue quechua. Fondée en 1987, héritière de celle de 1953, elle préconise et contribue à institutionnaliser un quechua impérial qui correspondrait à celui des glorieux ancêtres des Péruviens. Cette langue « réincaïsée » tient à se distinguer du quechua des Indiens qui souffrirait, selon les académiciens, des scories du métissage ${ }^{12}$.

\section{Du néo-incaïsme au New Age}

Ainsi, l'apologie de l'empire inca n'est pas une invention du New Age andin. Celui-ci est en effet lié à tout un mouvement néo-indien de revalorisation du passé préhispanique $^{13}$. La culture indigène qui alimente ce mouvement a déjà été transformée et urbanisée par cette revitalisation apologétique qui date du début $\mathrm{du} \mathrm{Xx}^{\mathrm{e}}$ siècle. On ne peut donc comprendre la genèse du New Age andin sans tenir compte du néo-incaïsme et, plus particulièrement, du renouveau actuel de celui-ci au Cuzco.

Au cours des premières décennies du $\mathrm{xx}^{\mathrm{e}}$ siècle, le mouvement indigéniste se charge de trouver à la nation péruvienne un ancêtre présentable qui permettrait d'ignorer l'autochtonie historique des indigènes andins méprisés par les élites créoles. Ce mouvement donne à la nostalgie de l'empire inca une dimension fondatrice: l'ensemble de la nation est invité à communier en elle pour se construire. Le sentiment national apparaît donc comme une sorte de contagion de nostalgie qui se métamorphose en autochtonie ${ }^{14}$. C'est ainsi que les indigénistes célèbrent l'Indien impérial. Cette représentation est évidemment d'origine européenne. Dans la tragédie donnée en 1763 par Le Blanc de Guillet (1782), l'empereur Manco Capac, modèle du bon despote des Lumières, proclame que l'État inca représente « l'état de nature de l'homme bon et égalitaire ». Les Incas de Marmontel (1895), paru pour la première fois en 1777, un an avant la mort de Jean-Jacques Rousseau, et largement diffusé, décrit le gouvernement des Incas comme « quasi institutionnel et plein d'un amour généreux », et le culte du Soleil comme « la plus pardonnable des erreurs ». Les intellectuels de la gauche péruvienne des années 1920 réinventent ce mythe du gouvernement parfait : c'est bien le socialisme que les Incas avaient créé, et la nécessité du retour à cette ère 
grandiose apparaît à la fois comme un credo nationaliste et comme la condition indispensable de l'avènement d'une Internationale des travailleurs. Pour ces savants péruviens, l'empire inca était un «État socialiste organisé selon les caractéristiques d'un État moderne». Il correspondait parfaitement à « la conscience de l'indigène » dans laquelle, pensaient-ils, « il existe une conviction bien enracinée du gouvernement populaire et du principe du libre-arbitre et, parallèlement, une conception de la coopération sociale et de la fraternité communautaire » (Sivirichi 1946, p. 21). C'est ainsi que s'élabore le mythe d'un État inca parfait et généreux, tandis qu'on réinvente au Cuzco le culte de la divinité solaire dans la cérémonie de l'Inti Raymi, comme nous le verrons plus loin.

Ce néo-incaïsme prend, depuis une dizaine d'années, des formes nouvelles (Galinier et Molinié 2006 ; Molinié 2009). Au Cuzco, l'architecture récente rappelle les bâtisses cyclopéennes des ancêtres. On érige des monuments à la mémoire de souverains mythiques comme Pachacuti. On vénère Pachamama, la Terre Mère déjà célébrée par les indigénistes et prête à accueillir la Mother Earth du New Age. Peu documentée par les textes coloniaux, la Pachamama des communautés traditionnelles est une entité surnaturelle, à la fois très localisée et multiple. Largement théorisée par les anthropologues, elle est devenue aujourd'hui une divinité globale, honorée non seulement par l'Internationale new age, mais aussi par les mouvements écologistes, les ONG et même l'UNESCO, générant le concept de " pachamamisation ». C'est avec la même emphase que les indigénistes des années 1930 et les Enfants du Verseau célèbrent la générosité de cette divinité, en contraste avec sa version indigène qui est dévorante et avide de sacrifices. De nombreux mouvements indianistes contemporains ont repris des anthropologues, héritiers des indigénistes, cette représentation maternelle de la déesse Terre et la diffusent chez les Indiens qui, à présent, informent l'ethnologue d'une Pachamama bienveillante made in USA.

Par ailleurs, le néo-culte solaire célébré au solstice de juin attire la foule persuadée d'assister à une cérémonie authentique des ancêtres préhispaniques (Figure 1). Inventé par les indigénistes en 1943, sur la base des descriptions de Garcilaso de la Vega (1960 [1609]), l'Inti Raymi s'est doté dans les années 1990 d'un Inca qui n'est plus, comme jadis, un acteur, mais un descendant « véritable » de la lignée d'Inca Roca. Alfredo Inca Roca, professeur à l'université agraire de Cuzco, affirme ne pas interpréter un rôle, mais exercer son ministère à l'occasion du néo-culte solaire ${ }^{15}$. Il peut produire des documents d'archives prouvant son ascendance et a constitué un conseil du Tawantinsuyu qui revendique une reconnaissance officielle.

La prophétie du retour de l'Inca semble s'accomplir non seulement à Cuzco, mais au niveau de la nation péruvienne. En effet, à beaucoup d'égards, le président de la République, Alejandro Toledo, qui a gouverné le Pérou de 2001 à 2006, se présentait comme un prétendant au trône de l'Inca. Déjà avant son élection, il avait organisé un meeting de soutien à Sacsahuaman, là même où se 


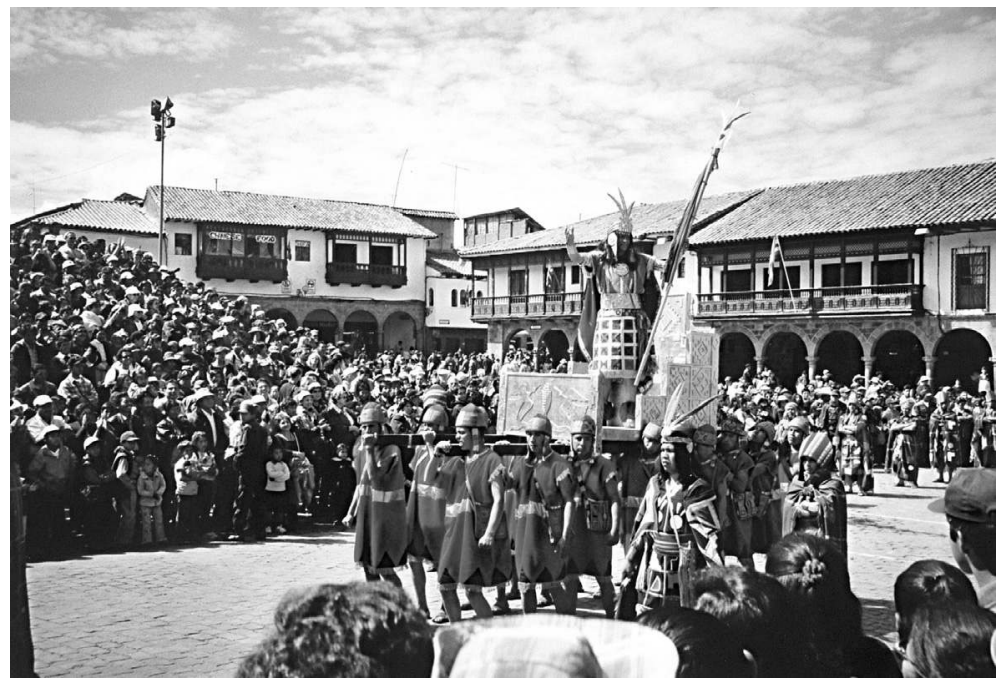

FIG. 1 - L'Inca du néo-culte solaire salue la foule sur la place d'Armes de Cuzco (cliché Molinié 2002).

célèbre, chaque année au solstice de juin, le néo-culte solaire de l'Inti Raymi. La dimension incaïque du président Toledo lui venait surtout de son intronisation dans les ruines majestueuses de Machu Picchu, le temple de l'incaïtude. Ici encore, le néo-incaïsme et le New Age se rejoignent puisque ce site est devenu la cathédrale des Enfants du Verseau. L'intronisation du président Toledo fut célébrée par plusieurs chamanes de la région ${ }^{16}$. Cette cérémonie locale avait la dimension internationale qui est celle d'un Inca global : les présidents de nombreux pays d'Amérique latine y assistaient aux côtés du ministre des Affaires étrangères d'Israël et de l'Infant d'Espagne. L'un des chamanes officiants était le recteur de l'université de Cuzco, un professeur d'anthropologie considéré au Cuzco comme un spécialiste de haut rang.

Les cérémonies néo-incas se développent partout dans la ville de Cuzco, dans les banques et dans les grandes surfaces pour la prospérité du commerce. Les hôtels de luxe affichent, à côté des services de coiffure ou de massage, celui de divination par les feuilles de coca, telle qu'on la pratique dans les communautés indiennes. L'une de ces dernières, celle des Q'ero, a été désignée comme particulièrement perfomante dans ces rituels car elle regrouperait les descendants directs des Incas. Ceux-ci, promus « fils légitimes du Soleil », ont été « découverts »en 1955 au cours d'une expédition d'universitaires de Cuzco. Cette tradition a été reprise par les Cuzquéniens ritualistes et même par des anthropologues (Flores Ochoa et Núñez del Prado 1984). Aujourd'hui, les Q'ero préparent des offrandes à la divinité de la terre et aux dieux des montagnes non seulement pour les hôtels de Cuzco, mais aussi, nous le verrons, pour les mystiques new age. 
Le rite le plus répandu chez les Andins est une offrande, appelée despacho ou pago ${ }^{17}$, faite aux divinités. Divers ingrédients sont disposés, selon un code très précis, dans l'espace rituel limité d'un tissu consacré (mesa). Le despacho est adressé par un spécialiste ( paqu) aux divinités des montagnes ou à celle de la terre à laquelle on demande de bonnes récoltes. Depuis une dizaine d'années, le rite du despacho connaît un succès étonnant auprès des populations métisse et blanche de Cuzco qui, avant, méprisaient ces manipulations idolâtres autant que les Indiens qui les pratiquent. Aujourd'hui, ce rite fait partie du sacrifice de lamas célèbré, chaque année, à l'université de Cuzco, par le recteur dont l'autorité académique s'est transformée en véritable prêtrise (Figure 2) ${ }^{18}$.

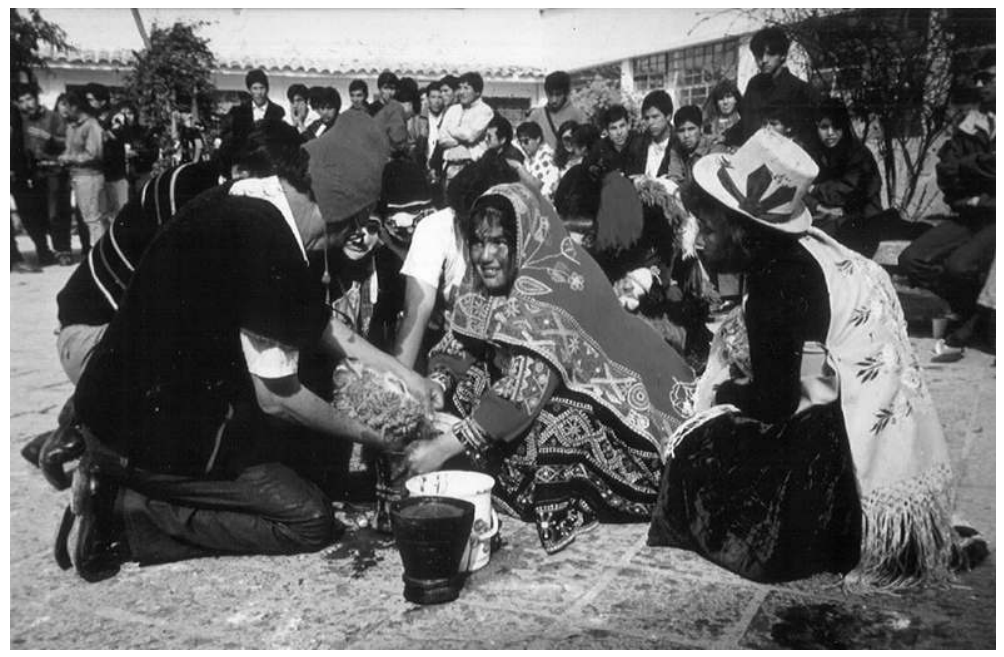

Fig. 2 - Sacrifice de lama a l’université de Cuzco (cliché Molinié 1997).

Pour la fête de la Pachamama qui a lieu le $1^{\mathrm{er}}$ août, ce recteur néo-chamane revêt sa tunique et sa coiffe « traditionnelles ». Il s'agenouille par terre au-dessus de la mesa sur laquelle il a disposé les ingrédients du despacho offert à la Terre Mère pour la prospérité du département d'anthropologie ${ }^{19}$. Il connaît bien les usages indigènes qu'il reproduit avec rigueur. Cependant, les ingrédients sont exceptionnellement nombreux. En fait, l'officiant a réuni diverses offrandes, celles pour la Pachamama, pour les divinités des montagnes, celles pour le retour de l'âme... Si chacun des ingrédients posés sur la mesa correspond à une offrande traditionnelle, en revanche, leur accumulation est une invention. Le despacho néo-inca procéderait-il par empilement ? Il correspondrait ainsi à une sorte de despacho moyen incluant l'ensemble des éléments qui composent la variété des despachos spécifiques, un peu comme une lengua general synthétise les dialectes 
ou comme l'idée new age d' « énergie » cumule des notions quechuas fort variées. Par ailleurs, si, dans sa forme traditionnelle, l'offrande est minimaliste et intime, celle du chamane-recteur est spectaculaire et publique. De l'encens brûle autour de la mesa et l'on remarque des vases cérémoniels en bois qu'on ne trouve guère dans un despacho traditionnel puisqu'il s'agit, en milieu universitaire, de pièces archéologiques. Leur présence « incaïse », en quelque sorte, un rituel qui, sans eux, ne serait qu'indien. Puis deux lamas sont amenés pour le sacrifice, les oreilles ornées des marques en laine de leur communauté d'origine. Le recteur-chamane leur donne à boire de la chicha (bière de maïs) comme le font les pasteurs des communautés à l'occasion du marquage des troupeaux. Puis il leur tranche la gorge et le sang dégouline sur le sol de l'université. Il est recueilli dans de grands vases anciens qualifiés d' " incas », et l'on passe alors aux deux rites suivants.

Le premier ressemble à celui qui est encore aujourd'hui pratiqué lors des sacrifices de lamas. Nous l'avons observé sur les hauts plateaux de Bolivie dans la région de Potosí à l'occasion de la préparation d'une bataille rituelle (tinku). Le sacrificateur avait trempé ses doigts dans le sang du lama et, sur le visage des participants, il avait tracé un mince trait d'une oreille à l'autre, en passant sur le nez. Les anciens Aymara pratiquaient cette peinture faciale avec le sang de vigognes lors de l'initiation des enfants ou sukullu (Bertonio 1984 [1612], p. 323 ; Bouysse-Cassagne 1987, p. 233). À l'université de Cuzco, le geste est moins délicat : le sacrificateur barbouille les visages avec un plaisir évident. Est-ce ainsi, en forçant le trait, que les néo-Indiens donnent à des pratiques réinventées leur efficacité symbolique? La deuxième séquence du rite évoque la fête incaïque de la Citua, célébrée au mois de septembre, au Cuzco, la capitale du royaume inca. Quatre cents hommes travestis en soldats, représentant les quatre quartiers de l'empire, étaient chargés de chasser les pestilences hors de la ville, tandis que les étrangers étaient provisoirement expulsés (Cobo 1964 [1653] ; Guaman Poma de Ayala 1980 [1615] ; Molina « el Cuzqueño» 1916 [1575]). Ceux-ci revenaient ensuite à Cuzco pour partager le sankhu qui consistait en une pâte de maïs malaxée avec du sang de lama sacrificiel. C'est ce que font maintenant les universitaires de Cuzco : le recteur fabrique ce sankhu cérémoniel avec de la farine mêlée au sang du lama qu'il vient d'égorger et en offre énergiquement à toute l'assistance malgré certaines réticences. Le visage ensanglanté, professeurs et étudiants communient religieusement dans ce qui est apparu aux conquistadors comme une eucharistie inca. Une fois de plus, un rite indigène réinventé, le sacrifice de lama, se voit ajouter une cérémonie inca, comme s'il fallait, à chaque fois, purifier les pratiques indiennes par celles de l'Indien impérial.

Il importe de noter que les néo-chamanes qui se déclarent ministres de ces nouveaux cultes font référence aux Incas et jamais aux Andins chez qui ils les ont observés. C'est à partir d'une «captation » quasi ethnographique de pratiques indigènes qu'apparaissent des formules nouvelles d'anciens rites. Des écrits historiques et ethnologiques viennent les nourrir et leur donner une légitimité que la 
seule indianité des origines ne saurait apporter. Les œuvres des universitaires sont ainsi recyclées dans des créations inattendues. L'authenticité n'a pas de valeur pour ces fabricants de rites, et l'anthropologue se retrouve dans une position d'expert, inspirant à son insu des productions incontrôlables. Le plus souvent, ces nouvelles cérémonies procèdent par empilement de coutumes et de croyances diverses, parfois contradictoires. Elles pratiquent un couper-coller sans souci de cohérence, ce qui leur permet une créativité admirable. Celle-ci est manifeste dans une cure magique, nommée ceq'esqa, que j'ai pu observer sur un malade venu en avion de Lima spécifiquement pour cela.

Après plusieurs heures de marche, nous sommes au pied du Picol, l'un des sommets les plus sacrés et puissants de la région. L'espace cérémoniel est idyllique, au bord d'une rivière, face à une cascade : le néo-chamane a l'habitude d'y pratiquer ses cures. Il s'agit d'abord de faire un despacho à Apu Picol. L'officiant a apporté pour cette divinité exigeante du vino de misa (vin de messe) : cette expression joue sur l'ambiguïté du mot misa. En espagnol, il signifie « messe ». En quechua, le mot espagnol mesa qui veut dire « table » est prononcé misa. Puis le néo-chamane offre à Apu Picol des feuilles de coca (qintu). Il procède ensuite à leur lecture divinatoire pour faire son diagnostic et prépare un despacho composé d'éléments traditionnels : de la graisse de lama, différentes plantes sauvages séchées, du riz, du sucre, des cacahuètes (le snack préféré de cet Apu), du papier d'aluminium or et argent (qori libro et qolqe libro), un écheveau de fils aux couleurs de l'arc-en-ciel, des morceaux de coton hydrophile, des bonbons, des grains de maïs, des confettis, de la terre provenant de lieux sacrés. Le néochamane revêt alors son unqu (tunique préhispanique). Il verse du vin dans un coquillage et propose à Apu Picol de se servir. Tous ces éléments sont ensuite emballés dans le papier sur lequel ils sont posés, et le paquet est brûlé cérémoniellement avec des prières. Cette première phase de la cure est fort semblable au despacho traditionnel offert aux dieux dans les communautés indiennes. La suite est plus surprenante.

Le malade s'étend sur le sol. Le néo-chamane serre tout le corps nu du patient dans deux fils avec lesquels il fait plusieurs tours comme s'il lardait un rosbif. Un fil est rouge, l'autre blanc : le premier est masculin, l'autre féminin, comme d'ailleurs, ajoute l'officiant, les deux œillets qui composent le despacho indien et les deux couleurs du drapeau péruvien, référence subtile à une autochtonie nationale sublimée. Le corps du malade est maintenant complètement ficelé. Le néo-chamane m'apprend que les fils rouge et blanc sont des ceques, ce qui explique le nom ceq'esqa donné à ce nouveau rituel. Cette référence à un système incaïque mérite une explication.

Au temple du Soleil de la capitale impériale de Cuzco (Coricancha) convergeaient 41 lignes (ceques) de 328 sanctuaires (huacas). Les points de l'horizon où se dirigeaient ces alignements de sanctuaires ou ceques étaient déterminés par des observations astronomiques. De telle sorte que ces lignes se déployaient tout 
autour du temple du Soleil selon le rythme des astres : les ceques correspondaient à des mois et formaient autour de la ville de Cuzco un gigantesque calendrier à la fois sidéral et synodal ${ }^{20}$. Des rites étaient célébrés sur ces sanctuaires à la date à laquelle ils correspondaient dans le calendrier (Figure 3). Ils étaient à la charge de chacune des unités sociales de Cuzco, celles-ci ayant sous leur responsabilité le culte de telle ou telle huaca sur tel ou tel ceque. Les alignements de sanctuaires, ou ceques, constituaient non seulement un immense calendrier déployé autour de la ville impériale, mais encore un ensemble de repères géographiques dans le territoire de Cuzco et, aussi, un registre de ses unités sociales puisque celles-ci se répartissaient les cultes rendus en chacun des sanctuaires alignés. Ce système organisait ainsi l'espace impérial, réglait le temps à travers le calendrier rituel qu'il formait et ordonnait la société qui rendait les cultes.

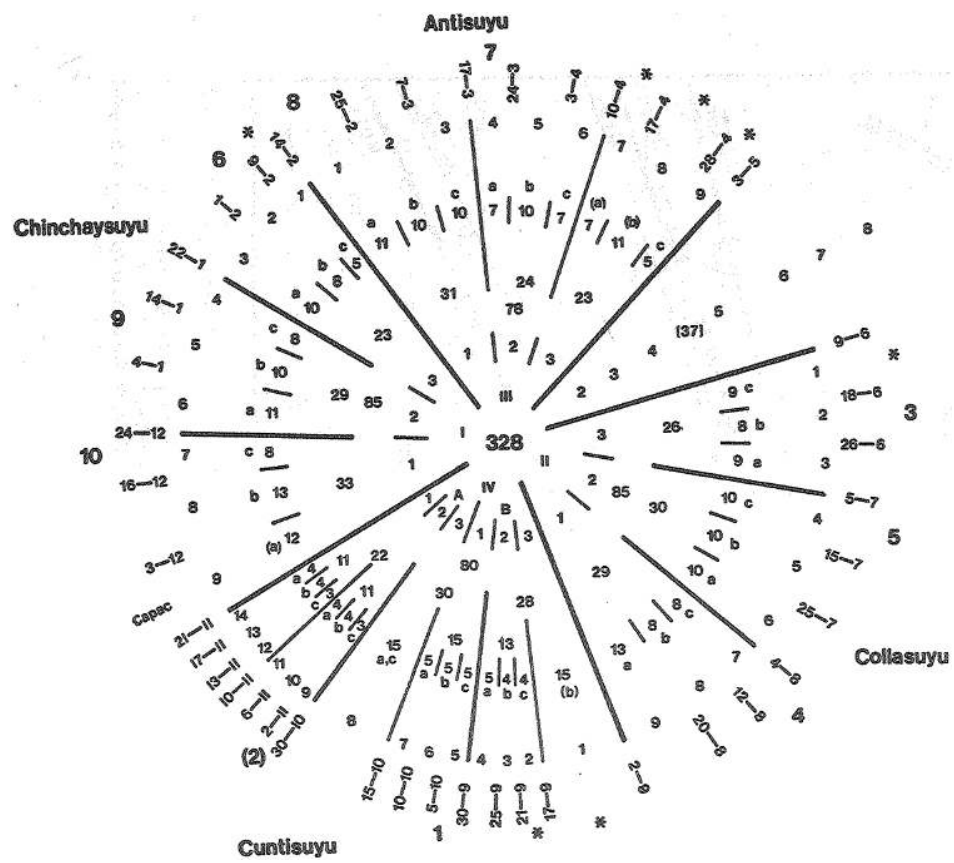

Cercles 1 et 2 : la classification des suyus et des groupes de trois ceques selon Zuidema (1964).

Cercles 3, 4, 5 : le nombre des huacas contenus dans les suyus, les groupes de trois ceques et les ceques. Cercle 5 : les noms des ceques : a, collana « principal »; b, payan « secondaire »; c, cayao " original ». Cercle 6 : la séquence des ceques donnée dans la " relación de las huacas » suivant l'ordre des suyus I, III, II et IV.

Cercle 7 : le calendrier; à chaque huaca est attribué l'espace d'un degré sur le cercle, chaque degré couvrant un jour.

Cercle 8 : les numéros et les astériques : les panacas et les ayllus pré-incas, mentionnés dans la « relación de las huacas $"$.

FIG. 3 - Le calendrier inca d'après le système des ceques (selon Zuidema 1986, p. 94). 
Revenons à la cure chamanique baptisée ceq'esqa. Notre question sur les liens entre les ceques incas et le corps ficelé de son patient parut à l'officiant complètement incongrue : comment ne pas comprendre, selon lui, que les ceques, ces alignements incas de lieux sacrés, étaient en réalité des "lignes d'énergie" ? Il était évident, pour lui, que celles-ci devaient guérir son patient ! Les fils qui nouent le corps de ce dernier créent, selon lui, des « circuits d'énergie » à l'instar des ceques autour de la ville impériale. Cette « énergie » des Incas ne pouvait donc que soigner le malade. Bien évidemment, dans les cures magiques traditionnelles pratiquées par les paqu dans les communautés, il n'y a pas la moindre référence aux Incas, encore moins aux ceques ou à des notions d' "énergie ».

Soudain d'un geste brusque, l'officiant coupe les fils qui lient son patient en criant en quechua "Kutiy! Kutiy! Kutiy carajo!", comme le font dans leurs cures les chamanes indiens des communautés. En ce cri de « Kutiy! Kutiy! », on reconnaît le définitif $d u$ verbe quechua signifiant "revenir en arrière». Le néo-chamane explique que c'est ainsi qu'il ordonne à l' " énergie négative » de s'en aller, un peu comme on disait jadis vade retro Satanas! Il fait référence à un rituel andin, appelé kutychi, auquel j'ai assisté bien souvent : celui-ci consiste en un pago pour le retour de l'âme emportée par le soq'a, la figure négative et mortifère de l'ancêtre préhumain (Molinié 1979). Mais cette référence à un élément de la culture indigène est ici hors contexte. Le néo-chamane suggère en riant que, pour les patients anglophones, cette dernière phase de la cérémonie est interprétée comme un "Cut it! Cut it! ", allusion au geste de couper (to cut) brusquement les fils qui nouent le corps du patient. On ne saura jamais s'il plaisantait ou s'il s'agissait d'une adaptation particulièrement ingénieuse d'un rite andin à la clientèle nord-américaine et européenne qui accourt aujourd'hui au Cuzco en quête d'énergie.

La cure ceq'esqa que nous venons de décrire illustre bien le processus d'invention de la tradition (Hobsbawm et Ranger 1983). La première partie ressemble à un despacho traditionnel. Elle correspond à la dimension « sauvage » du rituel inventé, auquel elle donne une légitimité d'autochtonie. La deuxième partie illustre l'incaïsation d'une pratique qui, sans cela, serait entachée de son origine indienne. Le néo-chamane procède par homologie de structure entre le corps du patient et le calendrier inca, entre l'espace corporel et celui de l'empire inca. En effet, l'ombilic du patient est aux différents membres et organes de ce dernier ce que la ville de Cuzco était à l'empire inca. Nous observons, dans cette cure, le recyclage d'une étude anthropologique du calendrier inca, particulièrement pertinent puisque le procédé d'analogie est caractéristique de la pensée andine. Ce n'est pas tout. Le néo-chamane introduit dans son invention un concept new age. En effet, les ceques, définis par Zuidema (1964) comme des alignements de lieux sacrés, deviennent, dans le cadre de la cure ceq'esqa, des vecteurs d'« énergie ». L'analogie et la dimension énergétiques de l'opération sont en plus liées puisque Qosqo, le nom nouveau de la capitale néo-inca, correspond au qosqo du 
patient, soit le mot new age qui désigne son plexus solaire. Du coup la sacralité indigène et locale prend la même dimension mondiale que celle des croyances du New Age par Incas interposés. Le procédé est le suivant : on retient une donnée de l'histoire des Incas (ici celle d'alignement de sanctuaires dans le système des ceques) que l'on sort de son contexte préhispanique; puis on l'accole à une pratique indigène (le despacho) ; enfin on introduit la notion new age d'énergie qui recycle le savoir local des anthropologues en théorie globale. Ces mécanismes de fabrication rituelle connaissent aujourd'hui des développements spectaculaires dans les pratiques des mystiques new age.

\section{Le New Age andin : LA Quête de L'InCa global}

Des despachos du New Age andin sont célébrés aux États-Unis, en Italie, en Scandinavie, en Espagne. Ils sont enseignés par des « maîtres » venus de Cuzco. Des Q'ero les accompagnent parfois, assumant le rôle prestigieux de « chamane traditionnel ». De retour chez eux, ces derniers reprennent leur statut d'Indiens pauvres. Aux Enfants du Verseau ils apportent l'« énergie » de la tradition inca et à leurs employeurs beaucoup de dollars.

$\mathrm{Si}$, chez les Runa ${ }^{21}$, on brûle le despacho en offrande à la divinité, chez les New Agers il est posé sur la tête ou le plexus solaire du commanditaire. Celui-ci ressent « l'énergie pénétrer en lui de la tête aux pieds » ou " une brûlure à la tête » ou " une émotion très forte de communion avec le prochain» ou, encore, «le sentiment de devenir un serpent». D'autres officiants ont des visions «d'un groupe de moines tibétains traversé par un rayon d'argent» ou bien «d'une éclipse de soleil avec un anneau d'or et une navette spatiale se déplaçant dans une grande chaleur $\gg{ }^{22}$.

Deux traits distinguent radicalement le despacho new age de l'original runa. Tout d'abord, les voies de leur efficacité sont fort différentes. Les Runa brûlent l'offrande qu'ils ont soigneusement préparée pour les dieux, tandis que les mystiques new age en font un paquet au contenu énergétique qui est posé sur la tête ou le plexus solaire du patient. Les officiants new age ont une démarche fort différente des spécialistes runa : si ces derniers font du despacho une offrande aux divinités des montagnes ou à la Terre, les Enfants du Verseau captent, quant à eux, de l'« énergie ». Les premiers donnent pour recevoir ; les seconds prennent pour vivre mieux. Dans le premier cas, le despacho est le véhicule d'un don; dans le second, il contient le bienfait recherché dans sa substance même. Dans la tradition andine de l'échange, les objets qui le composent sont destinés à nourrir les dieux. Dans la version new age de prédation, le despacho est chargé d' « énergie » captée, celle du « maître » et celle des millions d'Indiens qui participent à des rites de « tradition inca ». Ceux-ci sont ainsi transformés en pourvoyeurs d'énergie. 
Par ailleurs, si la composition runa du despacho varie par son objet et son destinataire, celle du despacho new age est propre à l'individualité de l'offrant : chacun a ses pierres magiques, sa petite touche personnelle et un ingrédient qui lui est spécifique. Cet individualisme semble logique puisque, contrairement aux Runa qui nourrissent leurs dieux par le biais d'un spécialiste, les New Agers se servent eux-mêmes en énergie. La globalisation et l'individualisme, caractéristiques du New Age, marquent le néo-despacho andin. Il reste que le despacho se prête à des pratiques extrêmement diverses : offert par les Runa pour la fertilité de la terre, préparé par un Q'ero pour l'inauguration d'une banque, célébré par le recteur de l'université pour un département d'ethnologie, adopté par les New Agers pour capter de l'énergie positive, il accompagne la supplique du grand prêtre lors de l'Inti Raymi aussi bien que l'intronisation du président de la République... La souplesse de cet outil rituel permet de le manipuler, de lui faire jouer alternativement le rôle d'offrande aux Apu, d'aspirateur d'énergie légère et de soufflerie d'énergie lourde. Cette malléabilité permet de l'adapter à toutes les occasions et de multiplier celles-ci à l'infini. La simplicité technique de son élaboration lui vaut d'être largement diffusé. La variété de sa composition autorise des combinaisons et des adaptations d'ingrédients puisque ceux-ci dépendent de la relation entre l'offrant et le contexte. Cependant toutes ces variations sont possibles seulement si l'on ignore un facteur essentiel de la pratique indienne : le pouvoir tout particulier du spécialiste qui élabore le despacho dans le contexte d'une culture andine spécifique et l'origine divine du don qu'il exerce $^{23}$.

Ces rites sont considérés comme plus efficaces par les New Agers quand ils sont pratiqués sur le lieu même de l'origine de l'énergie, autrement dit dans les ruines préhispaniques qui conservent l'énergie des Incas et à l'occasion des grandes cérémonies indiennes pendant lesquelles les Runa produisent de bonnes vibrations. Le «parcours initiatique » que nous allons décrire constitue, tout comme la cure ceq'esqa, une véritable invention de la tradition ${ }^{24}$. Il a été créé par Juan Núñez del Prado, ex-professeur d'anthropologie à l'université de Cuzco, qui affirme avoir suivi les différentes étapes de l'initiation pour obtenir le grade le plus élevé de chamane ${ }^{25}$. Son maître lui a appris un rite de « couronnement d'un roi sacré » (Núñez del Prado J. 1998 p. 45). À partir de son expérience, Juan Núñez del Prado a créé un itinéraire initiatique dont les étapes (la plupart dans des sites incas) sont celles de la révélation du futur Inca qui gouvernera lors de l'ère prochaine. Ce cycle rituel, entre pèlerinage et cérémonie d'initiation, est un bon exemple de rencontre entre le messianisme new age et le mythe andin du retour de l'Inca. Il montre aussi le rôle que joue l'anthropologie dans les réélaborations locales du New Age.

Le circuit mystique commence à la cathédrale de Cuzco où l'on sollicite, dans le hanaqpacha ${ }^{26}$, deux divinités du catholicisme local : la Virgen de la Natividad la Antigua qui accueille les fidèles à l'entrée dans la lumière aveuglante de la 
place d'Armes et Taytacha Temblores qui, très vénéré à Cuzco, est imploré au milieu des cierges et dans le murmure des suppliques indiennes. À ce couple de divinités, les New Agers attribuent l'harmonie du yin et du yang : elles produisent les énergies complémentaires, l'une masculine et l'autre féminine, qu'ils recueillent avec ferveur. Il ne s'agit pas de l'invention de deux icônes : ces deux divinités reçoivent, en effet, depuis des siècles, les prières des Cuzquéniens ${ }^{27}$. On notera que les adeptes du New Age andin n'ont pas seulement recours au passé préhispanique réinventé par les néo-Incas, mais aussi au christianisme local, fruit d'un alliage avec les croyances préhispaniques et générateur de vibrations à travers les rituels pratiqués par les Indiens.

Ce n'est pas tout. Dans cette même cathédrale, le groupe new age sollicite une étrange divinité qui est probablement plus ancienne que les deux images chrétiennes précédentes : il s'agit d'une pierre ovoïde qui sert à retenir l'immense porte de la cathédrale ouverte sur la place d'Armes. Mesurant environ 1,50 $\mathrm{m}$ de diamètre sur sa partie la plus large et $60 \mathrm{~cm}$ de haut, elle est soigneusement polie, avec une cavité d'une dizaine de centimètres en son centre. Cette pierre est, selon le néo-chamane qui accompagne le groupe, une khuya. Il fait ainsi référence à une croyance indigène que nous avons pu observer par ailleurs.

Les khuya, qu'on appelle aussi inqa, inqaychu, ylla ou khuya rumi, prennent la forme de miniatures de chacune des espèces animales ${ }^{28}$ : les bergers en distinguent pour chaque type d'animal (vaches, moutons, lamas ou alpacas) qu'ils élèvent et, aussi, pour certaines plantes cultivées comme le maïs. Ces amulettes sont considérées comme des prodiges de la nature et, de fait, elles sont souvent polies et même, paradoxalement, travaillées pour acquérir ce caractère d'exception. La khuya est porteuse d'une « essence-en-acte » propre à chaque bête, une « puissance d'animation » qui pousse cette essence à s'actualiser (Ricard Lanata 2010, p. 222). Les bergers les cachent dans des tissus précieux, les nourrissent, les potentialisent par des rituels célébrés à des dates précises. Les Apu, divinités des montagnes, animent les animaux et les plantes par le truchement de ces « forces d'accomplissement » (ibid., p. 121) que sont les khuya. Ce sont ces divinités qui les donnent aux humains.

Notons que la pierre qui retient la porte de la cathédrale, toute polie et possèdant une cavité en son centre, est considérée comme une khuya géante. Elle est l'objet d'une discrète dévotion indienne. Il y a quelques années, elle était reléguée dans le coin d'une chapelle de la cathédrale. À plusieurs reprises, les curés ont essayé de la faire disparaître, mais les protestations des Indiens les ont obligés à la replacer, cette fois comme coin de porte. Certains fidèles viennent de lointaines communautés pour lui faire des offrandes, plus particulièrement en août quand la Terre est ouverte et, surtout, à l'aube, à l'ouverture des portes de la cathédrale, quand personne ne les voit. Souvent ils se mettent d'accord avec le sacristain pour que la graisse de lama ou les feuilles de coca qu'ils ont apportées restent, quelque temps, près de la pierre sacrée. Ce culte est inconnu de la plupart 
des Cuzquéniens, tant il est vrai que ses fidèles sont rares et se limitent souvent à lever les mains quelques secondes en une invocation murmurée, avec un regard persécuté si propre aux Runa.

J. Núñez del Prado, l'inventeur du circuit rituel que nous décrivons, appelle cette pierre/khuya Hatun Taqe Wiraqocha, du nom de la divinité des Incas. En effet, un anthropologue de Cuzco (Valencia Espinoza 1991) a comparé cette pierre ovoïde à l'ovale du dessin de Pachacuti Yamqi (1950 [1613], p. 226) représentant le dieu Wiraqocha. Selon les New Agers, elle est capable d'absorber les énergies négatives ( hucha). Ici comme ailleurs, l'Indien et le New Ager ont un rapport inverse au sacré : le premier fait une offrande, le second se débarrasse de son énergie négative. Nous assistons ainsi au passage abrupt d'un culte indigène à un culte new age, avec un passage discret par la néo-incaïsation (à travers la référence à Wiraqocha) tel que nous l'avons déjà observé dans d'autres rituels. La khuya indienne est devenue khuya new age avec, pour seule transition, sa dissimulation derrière une porte. Les Enfants du Verseau vont-ils restituer aux Runa un dieu extirpé par les curés de la cathédrale ? Pendant que J. Núñez del Prado nous expliquait comment il fallait frotter cette pierre pour se libérer de son " énergie pesante », une vieille femme s'était agenouillée près d'elle, avait enlevé son chapeau et frotté doucement toute sa surface avec de la graisse de lama en murmurant des prières. Finalement, la khuya des Indiens, identifiée par un écrit néo-inca comme le dieu suprême Wiraqocha, passe de la fonction de coin de porte à celle de simple poubelle d'énergie.

La seconde étape du parcours initiatique des New Agers nous conduit à Q'enqo, un site inca situé près de Cuzco où les mystiques se retrouvent sur une " plate-forme de lumière » pour se débarrasser de l'énergie pesante résiduelle grâce à un despacho pratiqué par le maître du groupe. Puis, dans la grotte d'Amaru Machay, les futurs initiés sont invités à imaginer leur propre conception dans le ventre de leur mère. De cette façon, ils réussissent à " transférer leur cordon ombilical énergétique de leur génitrice à la Pachamama ». Ils sont, à présent, frères et sœurs puisque enfants de la même mère. Ils poursuivent leur voyage vers le lac Huacarpay qui est considéré comme le lieu de naissance de l'Inca Huascar: ils vont se connecter à l'esprit du dernier souverain du Tawantinsuyu. C'est à l'esprit de Pachacuti que les initiés vont ensuite se consacrer, au milieu des pierres cyclopéennes de la citadelle de Sacsahuaman.

Le groupe prend la route de Pisac et escalade les majestueux édifices incas accrochés à flanc de la cordillère. Les corps pesants des New Agers vacillent sur les pierres à pic, glissent sur les dalles des palais qui surplombent le vide. Pour capter les énergies des sommets qui entourent le site, ils utilisent le système des ceques (voir plus haut et Figure 3), ce qui ne facilite pas la tâche de l'ethnographe des New Agers à qui l'on demande une caution scientifique. En effet, l'un des rituels que les mystiques accomplissent devant moi consiste à capter l'« énergie des ceques » selon une théorie comparable à celle de la cure ceq'esqa décrite plus 
haut. Cette énergie se trouve capturée dans les niches des murs incas situés face aux sommets qui sont, pour les New Agers comme pour les Runa, des divinités. Nous découvrons qu'il existe des ceques new age établissant une connection mystérieuse entre des niches incas et des Apu vivants, autrement dit une relation entre, d'une part, les ancêtres incas dont les participants recherchent le futur souverain à travers ce rite, d'autre part, les dieux indigènes contemporains (Figure 4). Il y a dans les prières des mystiques, enfouies dans les niches en ruine, comme le tracé d'une généalogie avec, en plus, la référence «scientifique », bien que tronquée, à l'anthropologue Zuidema (1964). La culture new age sur fond d'anthropologie prend toute sa cohérence : de la cure ceq'esqa pratiquée par un néo-Inca, aux mystiques new age en quête du prochain Inca, la notion de ceque recyclée acquiert une étonnante efficacité symbolique.

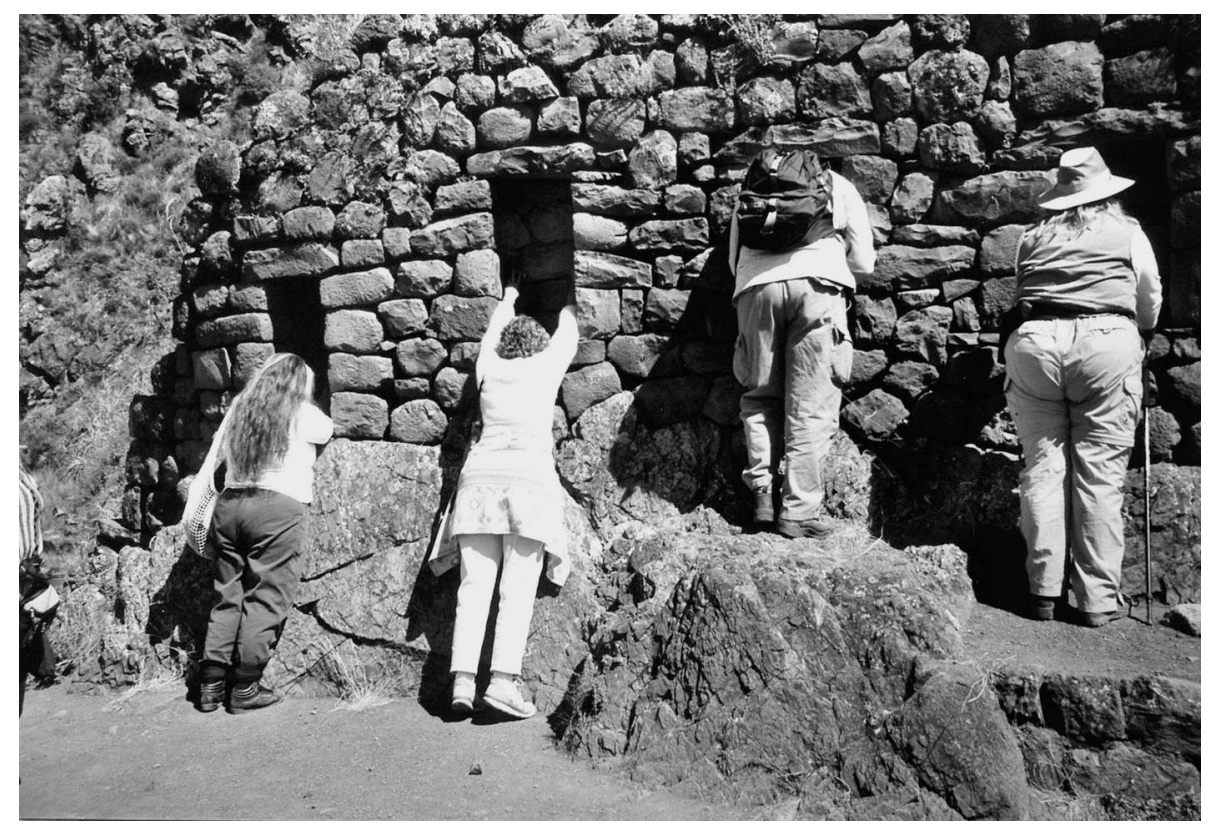

FIG. 4 - Des mystiques New Agers recueillent l'« énergie des ceques » dans les niches de ruines incas (cliché Molinié 2002).

Nous poursuivons la quête vers Ollantaytambo. Les New Agers n'ont pas l'air surpris par la stupéfiante beauté du site. Ils sont occupés à ouvrir l'« œil de leur gorge » pour y faire entrer l'esprit du Vent qui s'engouffre en rafales dans Wayrapunk'u (Porte du Vent) face au pic de la Verónica superbement enneigé. L'initiation se poursuit à Machu Picchu qui est pris d'assaut par les groupes ésotériques. Ceux-ci se disputent les temples, un peu comme à Jérusalem les Églises se battent pour célébrer la messe sur le tombeau de Jésus-Christ. 
Des groupes s'y introduisent la nuit et sont parfois victimes d'accidents inévitables tant le site est escarpé. Les archéologues se plaignent des dégâts irréparables qu'ils causent. Dans ces ruines somptueuses, le « maître » identifie des temples pourtant inconnus des archéologues. Il investit celui du Condor en précisant que cet animal représente l'esprit collectif de tous les Andins. Les Nord-Américains du groupe sont, dit le maître, porteurs de l'esprit de l'Aigle. Il faut donc utiliser ici l'énergie yanantin dégagée par le couple que forment le condor et l'aigle.

L'étape suivante du circuit initiatique est le gigantesque temple de Wiraqocha situé à quelques kilomètres de Cuzco. On sait que les Espagnols prirent cette divinité pour un équivalent du dieu des chrétiens, opposant ainsi son culte à celui du Soleil qui leur apparaissait comme une idolâtrie. Cette théorie semble être aussi celle des New Agers qui affirment se trouver dans le temple de Javeh. Si, à Cuzco, ils ont « travaillé » avec le monde d'ici (kaypacha) et à Machu Picchu avec le monde souterrain (ukupacha), ils vont à présent aborder le hanaqpacha, soit le monde supérieur. Dans ce temple, les douze familles royales, leur dit-on, se réunissaient pour choisir, parmi douze candidats, celui qui serait le prochain Inca. Ce dernier était signalé par une lueur surnaturelle : celle d'un prêtre du sixième grade. C'est lors de cette dernière étape que doivent surgir les candidats aux fonctions d'Inca. Ils devront suivre un parcours initiatique tout au long de la cordillère et se rendre à Lima auprès du Cristo de los Milagros, le Christ des Miracles.

On a vu comment le messianisme rend possible une convergence entre la tradition andine et les conceptions du New Age. Le retour de l'Inca s'exprime dans ses résurrections récurrentes dont nous avons vu quelques exemples: Inkarrí dans le mythe, Tupac Amaru dans la révolte anti-coloniale du XVIII ${ }^{\mathrm{e}}$ siècle (O'Phelan Godoy 1995), le descendant d'Inca Roca dans le culte solaire, Alejandro Toledo à la présidence de la République... Il manquait l'Inca du New Age et c'est un anthropologue, ex-professeur à l'université de Cuzco, qui l'a créé, cumulant ainsi les titres d'universitaire, de chamane et, comme nous allons le voir, de tour operator.

Ce parcours rituel est en effet vendu sur un site web par des agences de Cuzco ${ }^{29}$. Les guides sont qualifiés de « maîtres indigènes de la tradition andine ». Les Q'ero sont exhibés comme les derniers descendants des Incas et sont montrés vêtus de ponchos (qu'ils ne portent jamais chez eux). On apprend aussi qu'il existe désormais une demi-douzaine de prêtres à l'échelle mondiale qui sont des sortes d'intermédiaires à la fois mystiques et financiers. Des conférences sont proposées dans le monde entier, comme l'indique la Wiraqocha Fonden Skandinavien sur son site. Un promoteur de tourisme ésotérique nous a d'ailleurs précisé qu'il pouvait pratiquer les rituels andins en Autriche et dans le nord de l'Italie où les montagnes sont suffisamment hautes pour procurer des énergies semblables à celles des Andes.

Le tourisme mystique est anobli par des réunions internationales. Ainsi l'Institut Intiq Amarunkuna et la Communauté mondiale d'Amérique indienne 
solaire organisèrent, en août 1992, un congrès mondial pour célébrer le « Retour du $\mathrm{X}^{\mathrm{e}}$ Pachacuteq » et « boire aux sources de la sagesse andine ». Cette manifestation était placée sous le patronage de la mairie de Cuzco, de l'Institut national de la culture et de l'université de Cuzco. La même année, la ville impériale fut le siège de la première Rencontre internationale holistique. Son programme proposait des cérémonies d'offrandes aux dieux des montagnes, des visites aux bains médicinaux de Machu Picchu, des concerts de musique andine, des conférences sur les thèmes : «Mourir c'est rentrer chez soi », « Le chemin de la véritable initiation », " Comment vivre dans la Lumière », " Initiation et contre-initiation dans les temps modernes », «Le mental dans la matière et la matière dans l'Esprit », etc. En 1995, une International Peace Conference a été organisée au Carleton College à Northfield dans le Minnesota par l'International Institute of Integral Human Sciences Inc. Cette réunion proposait une rencontre avec les moines tibétains de Gyuto, mais aussi une journée en compagnie de Willaru Huayra de Cuzco pour parler du «message de la prophétie inca ». Celle-ci annonçait que, lorsque le Condor du Sud rencontrera l'Aigle du Nord, « l'esprit de Mother Earth se réveillera et des milliers de ses enfants avec elle ».

Dans les pratiques new age, si on observe la récupération de représentations néo-incas préalablement élaborées, on est frappé par l'absence de référence explicite à la culture indigène. Il semble même que les New Agers préfèrent éviter les Runa. Par exemple, ceux que nous avons rencontrés se rendent, par le biais d'une agence, au pèlerinage de Qoyllurit'i auquel participent de nombreuses communautés indiennes avec leurs danses spectaculaires. Ces communautés proprement dites n'ont pas l'air d'intéresser les mystiques new age. Ce qui semble en revanche les préoccuper, c'est d'attendre la fin des cérémonies et le départ des pèlerins pour aller capter les bonnes « vibrations » que ces derniers ont produites. Comme si le paysage, en sa matérialité tellurique, recueillait quelque chose de la sacralité de ces pratiques, celle-ci étant ensuite captée par les mystiques new age à travers leurs rites.

Ceux-ci semblent aussi peu intéressés par les rites néo-incas dont ils recueillent pourtant les représentations. C'est le cas du néo-culte solaire qui se diffuse actuellement dans les communautés traditionnelles de la région de Cuzco et, même, des Andes centrales. Par exemple, dans les ruines de Moray près du village de Maras, un Inti Raymi est célébré au solstice de juin sur le modèle de celui de Cuzco. Les enfants des écoles forment les armées du Tawantinsuyu, tandis que l'Inca local revêt le manteau de son homologue cuzquénien fabriqué en ailes de chauve-souris. Un chamane runa descend des communautés d'altitude pour offrir un despacho. Les maires métisses des villages voisins se métamorphosent en ministres de l'Inca. Ils revêtent pour l'occasion des ponchos comme ceux des Indiens qu'ils méprisent par ailleurs. Ces derniers viennent de leurs communautés assister au culte dont on leur a dit qu'il était celui de leurs ancêtres : ils envahissent les ruines pour assister à ce nouveau rituel. Il est trop tôt pour 
savoir ce qu'ils en feront. Cependant, l'introduction d'une célébration néo-inca dans une communauté traditionnelle que nous avons observée le $1^{\text {er }}$ août 2002 peut donner des indications sur l'impact de ces nouvelles pratiques sur les Runa.

\section{L'IRRUPTION DANS LA COMMUNAUTÉ INDIGÈNE DE LA TRADITION RÉINVENTÉE}

Ce jour-là, la communauté de Ccatca fête la Pachamama pour la cinquième fois. Le maire et le gouverneur de la région président une cérémonie qui est traditionnellement célébrée dans l'intimité des familles. De chaque côté de ces autoridades, les vingt-quatre regidores des communautés indigènes tiennent leurs varas à la main, des bâtons cérémoniels en bois cerclés d'argent, symboles de leur fonction de gouvernement communautaire. Ils sont, selon la tradition, divisés en deux moitiés de douze, à droite et à gauche du podium officiel, l'une regroupant ceux de la région de Quispicanchis, l'autre ceux de la région de Paucartambo. Les uns jouent du pututo, conques dont l'écho marin se perd dans la cordillère, les autres de l'antara, flûtes de pan qui sont divisées en mâles et femelles. Ils portent leurs habits de fête, des ponchos aux motifs de leurs ayllu respectifs et des chapeaux ronds à rubans multicolores. Les autoridades ont revêtu des ponchos et des bonnets, contrairement à la coutume qui veut que ces notables portent un complet veston et un chapeau. Sur le poncho dont il se déguise, le maire porte son écharpe : le drapeau du Tawantinsuyu aux couleurs de l'arc-en-ciel. Un personnage venu de Cuzco se joint à eux, revêtu lui aussi d'un poncho : c'est le recteur de l'université de Cuzco. Il a fait le voyage pour assister au Pachamama Raymi (fête de Pachamama) qu'a scénographié le responsable des relations publiques de la même université.

Sur la place est dressée une sorte d'estrade comparable à celle de l'Inti Raymi cuzquénien, dont on dit que c'est un ushnu ${ }^{30}$. Les regidores se placent autour. Sont annoncés très fort, grâce à un haut-parleur, le « nouveau rituel » qui va être célébré et la «musique de chambre » qu'on va pouvoir entendre. La chaîne haute-fidélité est impressionnante. Les musiciens de l'orchestre sont assis sur des chaises qu'on ne voit jamais dans les communautés. Les regidores sont debout et mettent leurs pututu et leurs antara sous leurs ponchos. La représentation commence avec des mouvements de scène très semblables à ceux de l'Inti Raymi. Quatre Incas, deux en vert et deux en rouge, se dirigent vers un bûcher solennellement allumé par un Grand Prêtre. Soudain, l'Inca est capturé. Un prêtre lui présente la Bible. Comme dans l'emprisonnement d'Atahualpa, tel qu'il est rapporté dans les chroniques, l'Inca la jette à terre et les Espagnols tirent des coups de feu. Une croix est alors érigée sur l'estrade. On a voulu apparemment inventer une danza de la Conquista, mais sans les Indiens et avec des étudiants de l'université de Cuzco. Les quatre Incas saluent les autoridades et celles-ci s'inclinent respectueusement : devant les acteurs ou devant les Incas ? Le Grand Prêtre est appelé paqu, comme le spécialiste rituel dans les communautés indiennes. Il va 
jeter dans le fleuve les offrandes qu'il a composées, accompagné des vingt-quatre regidores. Est-ce un acteur de Cuzco ou un officiant de l'une des communautés? Rien ne permet de le savoir. Puis, les acteurs déguisés venus de Cuzco et les regidores sont intimement mêlés, mais il est clair que ceux-ci obéissent à ceux-là. Certains habitants de Ccatca suivent également l'offrande qui va être jetée dans la rivière et y versent de la bière. Pachamama, dont on célèbre la fête, acceptera-telle cette offrande faite de théâtre universitaire et de despacho traditionnel? Comme nous l'avions observé dans l'Inti Raymi, on ne sait plus s'il s'agit d'une représentation théâtrale ou d'un rituel.

Les membres des communautés indigènes et, en particulier, les femmes des regidores ne semblent pas se poser ce problème. Pendant que leurs maris « officient » sur la place, elles se tiennent à flanc de montagne comme si elles voulaient rester à l'écart tout en étant présentes car, depuis leur promontoire, elles peuvent tout observer. Divisées en deux groupes, correspondant aux deux moitiés auxquelles elles appartiennent, elles sont assises en deux files de six, parallèles à la pente, celles qui portent un chapeau se tenant plus haut que les autres qui sont tête nue. Elles échangent des bouquets de feuilles de coca. Les premières restent assises et les secondes les assistent, se lèvent à tour de rôle et font circuler la coca entre leurs « maîtresses ». Sans entrer dans les détails d'une cérémonie, cette fois traditionnelle, nous voulons simplement souligner la complexité de la situation. Deux groupes s'opposent, celui de la place où se déroule le Pachamama Raymi et, un peu plus haut, celui des communautés, notamment des femmes qui poursuivent tranquillement leurs rites tout en observant la scène. Celle-ci comprend deux types de participants : des acteurs venus de Cuzco et quelques figurants runa. Ensemble ils font une offrande à Pachamama qui, au lieu d'être célébrée dans l'intimité d'une communauté, est théâtralisée sur la place du village.

Chacun tient, dans ce rituel, le rôle qui est le sien dans la hiérarchie sociale du quotidien, même si la confusion existe entre l'acteur de théâtre et l'acteur du rite. Ce n'est pas la première fois que des Runa se prêtent aux fantaisies des misti depuis leur christianisation. Parmi les gens venus de Cuzco, il y a, rappelons-le, le maire, le gouverneur, le recteur de l'université et quelques professeurs d'anthropologie, une énergie prosélyte qui ne peut qu'évoquer celle des missionnaires de l'époque coloniale. En effet, on peut penser que la christianisation des communautés indigènes a fait appel à ce type de procédé, enrôlant leurs habitants dans des processions, des messes et des neuvaines. Imaginons simplement des missionnaires à la place des universitaires. La scène pouvait comporter des éléments identiques. Une différence majeure serait néanmoins notable : si les curés prêchaient un dieu et une doctrine qu'ils savaient extérieurs aux indigènes païens, les universitaires prêchent aux Runa ce qu'ils considèrent être leurs croyances et leurs rituels, mais dans une version purifiée d'indianité. Ils pensent revitaliser une tradition qui a dégénéré : c'est ainsi qu'on honore la Pachamama en Indiens étatiques sur la place et non en Indiens archaïques au fond d'une 
masure. Par ailleurs, contrairement aux universitaires et aux autoridades, les missionnaires coloniaux n'étaient pas déguisés en Indiens. Au contraire, ils entendaient s'en démarquer. Il est clair qu'on assiste à Ccatca à une séance de néo-incaïsation de la tradition qui se répète dans toutes les communautés annonçant un Pachamama Raymi.

Pour finir, le recteur de l'université prononce un discours : il remercie le maire de Ccatca de "sauver une fête traditionnelle, une authentique fête andine » et lui remet une sorte de parchemin avec l'éloge de cette cérémonie ancienne. Un document écrit vient sceller l'antiquité du rite que l'on vient d'inventer. Le maire de Ccatca répond d'abord en espagnol puis en quechua : la « liturgie andine » qui vient d'être célébrée désigne Ccatca comme « capitale de la spiritualité andine ». C'est la publicité qu'on peut lire désormais sur le panneau à l'entrée du village. Quant au scénographe de ce rituel antique, il est émerveillé parce que, pour enterrer l'une des offrandes à Pachamama, les Indiens ont creusé le trou de leurs propres mains. Il les appelle waway, " enfants », comme le font les curés. L'orchestre de chambre cède la place aux danses folkloriques exécutées par des membres des communautés qui ont troqué leur vêtement de Runa pour un déguisement d'Indien. Après avoir été captée, purifiée et impérialisée, la tradition revient chez les Andins.

Il n'y avait point encore de New Agers à Ccatca lors de ma visite, en 2002. Mais tout était prêt pour transformer cette dévotion à Pachamama en culte à la Mother Earth. En revanche, à quelques kilomètres de Cuzco, des mystiques new age viennent se recueillir dans les ruines de Moray où se déroule un néo-culte solaire, semblable à celui de l'Inti Raymi que nous avons décrit plus haut. Ils captent, d'une part, l'énergie des Incas historiques dans les ruines, d'autre part, les vibrations de la cérémonie néo-inca contemporaine. Après l'Inti Raymi célébré sur les terrasses admirables, on les voit assis en tailleur dans un creux situé au milieu de l'amphithéâtre : ils se connectent avec Pachamama/Mother Earth. En ce même lieu, en des moments différents, et peut-être ensemble, on peut rencontrer des Indiens qui font paître leurs moutons, des adeptes du néo-culte solaire, des armées préhispaniques, des chamanes des communautés d'altitude, des New Agers californiens en méditation... C'est bien de ce télescopage prodigieux des temps, des espaces et des cultures que surgit le New Age andin.

Ce mouvement trouve sa légitimation dans l'agence nationale de tourisme qui en fait l'éloge dans ses prospectus. Le Fondo de Promoción Turística (FOPTUR) propose le Pérou comme centre magnétique de la planète, l'énergie s'étant déplacée de l'Inde et de ses gurus à la cordillère andine et ses Indiens. Plus particulièrement, Machu Picchu est perçu comme chakra planétaire où doivent se rendre les mystiques du monde entier (Longato 1991, p. 25, cité dans Pilares Villa 1992, p. 36). FOPTUR ne se limite pas à vanter les mérites des ruines : il vend également la culture traditionnelle plus ou moins réinventée. Sous la rubrique Cosmovisión religiosa andina, l'un de ses prospectus dresse une liste d'entités 
surnaturelles dans un invraisemblable désordre, comme si l'agence cherchait à les vendre en vrac sur un stand du marché de Cuzco. Enfin, le directeur de l'Institut national de la culture de Cuzco (INC) en 1995 ne cachait pas son attachement à la nouvelle « cosmovision » andine, en particulier dans son livre sur l'« interprétation mystique » du site de Sacsahuaman (Altamirano 1993). Les considérations d'Altamirano sur les chakras par lesquelles doit rentrer l'énergie du site, sur le vol conjoint du condor et de l'aigle ou sur le serpent de lumière cosmique sont d'autant plus déroutantes qu'il dirigeait, au moment de la parution de son livre, l'institution à laquelle sont confiés les restes archéologiques de la région. Ignorait-il les dégâts causés par les groupes de touristes mystiques aussi bien à Sacsahuaman qu'à Machu Picchu ? L'État péruvien, à travers ses deux représentations ministérielles les plus concernées (FOPTUR et l'Institut national de la culture), ainsi que par le biais de l'université, représentée par des anthropologues, a définitivement institutionnalisé à Cuzco le New Age andin.

\section{Conclusions}

La résurrection de l'Inca que prédit le mythe local d'Inkarrí prend désormais une dimension globale, celle du New Age. L'Internationale inca s'empare d'une tradition élaborée, à partir d'un mythe indigène, par les néo-Incas de Cuzco. Ceux-ci ont incaïsé la culture locale indigène, en particulier à travers le mouvement indigéniste. Par exemple, dans un despacho ou dans un sacrifice de lamas, on peut voir un néo-chamane insérer un vase d'origine archéologique pour anoblir le scénario. On peut aussi avoir recours à une cérémonie inca sortie de son contexte préhispanique et adaptée à une action rituelle contemporaine, par exemple le sankhu de la Citua consommé à l'université de Cuzco après le sacrifice des lamas. À l'inverse, il est possible d'insérer des gestes ou des éléments indigènes contemporains dans les cérémonies réinventées comme celle du néo-culte solaire lors de l'Inti Raymi : c'est le cas de l'offrande de chicha à la Terre, de la lecture des feuilles de coca par le Grand Prêtre et des danses autour du trône du souverain. Du coup ces gestes, indiens dans leur milieu d'origine, deviennent impériaux par leur présence dans un dispositif inca. Dans tous ces cas, il s'agit de trouver des iconographies intermédiaires entre l'Indien sociologique et la figure impériale, de manière à anoblir le premier et à autochtoniser la seconde.

Ces représentations néo-incas ont été nationalisées pour donner corps à une autochtonie mythique des Péruviens, celle qu'incarne l'Indien étatique. Elles sont aujourd'hui projetées sur le marché mondial où elles fusionnent avec celles du New Age. Des pans entiers de la culture andine rentrent ainsi dans un processus de globalisation qui parachève son parcours de la communauté au village mondial. Il s'agit probablement d'un processus commun à d'autres cultures, et certains diront qu'on n'aborde ici qu'une variante d'un processus 
plus général. Il ne suffit pas d'identifier ce thème et d'en décliner les variations, ni de globaliser la globalisation comme la plupart des études trop générales sur le New Age le font. Il faut étudier, dans chaque cas, les mécanismes spécifiques de cette transformation à partir d'une ethnographie précise. C'est ainsi que nous avons saisi les procédés de l'invention du New Age andin : les indigénistes ont impérialisé la tradition, les néo-Incas l'ont nationalisée, les adeptes néo-indiens du New Age la mondialisent. Ce n'est que la dernière étape d'une ethnogenèse qui est à suivre.

Il semble que la valeur nationale du néo-incaïsme est progressivement dépassée par une dimension internationale spectaculaire. Non par les idées socialistes des indigénistes comme Mariátegui, mais par les notions d'énergie, de vibrations et de Mother Earth véhiculées par le New Age et le tourisme mystique. Après avoir servi aux fondements symboliques de la nation, le néo-incaïsme est progressivement dénationalisé et se dissout dans un New Age globalisé. À peine la nation péruvienne est-elle consolidée par le mythe de l'Indien étatique que déjà se mondialisent les fondements imaginaires d'où elle a surgi. La résurrection de l'Inca, dans sa forme globale, retrouve la dimension cosmique donnée à Inkarrí par les Indiens vaincus et colonisés. Ceux-ci ont donné leur tribut, leur terre, leur minerai, leur travail, et aussi leur histoire à des fins d'autochtonisation des élites républicaines. Ils sont à présent appelés à offrir leur énergie tellurique au monde entier : un bien virtuel qui prend un sens tout particulier dans le marché de la finance internationale de ce $\mathrm{XXI}^{\mathrm{e}}$ siècle. *

* Manuscrit reçu en janvier 2011, accepté pour publication en février 2012.

\section{Notes}

1. « Inkarrí » vient de l'espagnol « Inca rey ». Ce mythe possède plusieurs variantes. C'est dans la région de Cuzco en 1955 que la première version fut recueillie, lors d'une expédition organisée par l'université de Cuzco (Núñez del Prado O. 1973). La version du mythe fut publiée en espagnol puis en quechua (Arguedas 1968). Un volume édité par Ossio (1973) rassembla bientôt diverses variantes recueillies dans différentes régions du Pérou. Voir aussi Burga (1988), Valderrama et Escalante (1995).

2. "La sangre de Inkarrí está viva en el fondo de nuestra Madre Tierra. Se afirma que llegará el día en que su cabeza, su sangre, su cuerpo habrán de juntarse. Ese día amanecerá en el anochecer, los reptiles volarán. Se secará la laguna de Parinacochas, entonces el hermoso y gran Pueblo que nuestro Inkarrí no pudo concluir será de nuevo visible » (Ortiz Rescaniere 1973, p. 139).

3. Le New Age est un courant de pensée né en Californie dans les années 1960 caractérisé par une conception individuelle et éclectique de la spiritualité, par un « bricolage » de croyances et de pratiques dont la cohérence n'est pas recherchée. Répandu essentiellement dans les pays anglo-saxons et européens, il comprend des mouvements fort divers dont la vocation commune est de transformer les individus par l'éveil spirituel. Il a une approche messianique de l'humanité qu'il pense pouvoir changer par des pratiques plus ou moins rituelles, par la méditation et par une démarche écologique de la vie quotidienne. Comme on le verra ici, il est très perméable aux cultures traditionnelles. Pour un panorama du New Age dont nous ne pouvons pas ici détailler les idées, voir Ferguson (1981), Vernette (1992), Dousset (1999).

4. Pour une première étude de ce processus voir Molinié (2009). Nous n'aborderons pas ici les problèmes théoriques que posent les notions de métissage et autres syncrétismes, de même 
que nous ne nous intéresserons pas aux débats sur la globalisation de la culture et autres mondialisations.

5. Les adeptes du New Age croient qu'en ce début de siècle l'ère de la constellation du Poisson s'achève pour faire place, après 2160 ans, à l'ère de la constellation du Verseau. Si la première était caractérisée par l'importance de la religion et de la guerre, la seconde devrait apporter l'harmonie universelle et la conscience de soi (voir Le Cour 1986 [1937]).

6. Pour la notion de pachacuti, trop complexe pour être développée ici, voir Bouysse-Cassagne et Harris (1987).

7. Nom par lequel on désigne souvent les adeptes du New Age (Ferguson 1981).

8. Pour plus de données sur le New Age andin, voir Cumes et Lizárraga (1999), Jenkins (1997), Parisi Wilcox et Jenkins (1996), Núñez del Prado J. (1998), Sullivan (1999).

9. Accord municipal 78 du 23 juin 1990. Garcilaso de la Vega (1960 [1609]) affirme que qosqo signifie en quechua «nombril ». En réalité, l'étymologie de ce mot ne s'explique pas par le quechua (Itier 1997, p. 152).

10. Sur le néo-incaïsme, voir Molinié (1996, 2004, 2009).

11. Cette version est celle de la municipalité de Cuzco, seule responsable de la graphie.

12. Pour une étude critique de ce néo-quechua, voir Itier (2009)

13. Pour une étude du mouvement néo-Indien, voir Galinier et Molinié (2006).

14. Cette nostalgie a certainement un lien avec la "tristesse de l'Indien » qui a fait l'objet d'une représentation répandue dès le XVI $\mathrm{e}^{\mathrm{e}}$ siècle (voir Estenssoro 1992). Les principaux auteurs de l'indigénisme péruvien qu'on ne peut étudier ici en détail sont Mariátegui (1928), Uriel García (1973 [1930]) et Valcárcel (1927). Pour une analyse du mythe de l'Inca, voir Burga (1988) et Flores Galindo (1986). Pour une histoire de l'indigénisme cuzquénien, voir Tamayo Herrera (1980).

15. Je remercie Alfredo Inca Roca pour sa collaboration et son aide.

16. Plusieurs années après, le président de la République bolivienne, Evo Morales, s'est prêté, dans les ruines de Tiahuanaco, à une cérémonie comparable quoique dans un contexte politique fort différent. Au nord du Pérou, des néo-Mochica célèbrent désormais le seigneur de Sipán au cours d'un rituel organisé près du musée/panthéon qui expose le produit des fouilles de sa tombe.

17. Les Andins pratiquent le culte des montagnes et leur médecine consiste souvent en des offrandes faites à ces divinités appelées Apu. Ces dernières ont leur propre hiérarchie et leurs propres liens de parenté. Voir, par exemple, Ricard Lanata (2010). Pour l'étude d'un despacho traditionnel, voir Molinié (1979).

18. Je remercie Aurelio Carmona pour sa collaboration et son aide.

19. Actuellement, cette cérémonie est célébrée dans le stade de Cuzco, l'université ne pouvant plus contenir le public qui ne cesse d'augmenter. Elle fait l'objet d'une charge (ou cargo) qui passe, chaque année, d'un professeur à l'autre.

20. Le système de ceques a été décrit par Zuidema $(1964,2010)$ sur la base de données recueillies au XVII ${ }^{\mathrm{e}}$ siècle par Cobo (1964 [1653]). Plus récemment, Bauer (1998) a tenté d'établir une cartographie précise de ce système à partir des données archéologiques.

21. Runa signifie en quechua " être humain », " personne ». C'est le terme par lequel s'identifient généralement les Quechuas par opposition à misti qui désigne le Blanc.

22. Témoignages recueillis par mes soins auprès des membres d'un groupe de touristes mystiques en juin 2002, dans les ruines de Pisac.

23. Dans les communautés quechuas, le paqu est un médiateur entre les mondes naturel et surnaturel. Il a le pouvoir d'alimenter les dieux des montagnes et la divinité de la terre. Il est d'un rang inférieur à celui de l'altumisayuq qui peut, quant à lui, convoquer ces divinités la nuit sur une table rituelle, dialoguer avec elles et les faire intervenir sur ses patients.

24. Les données qui suivent sont le fruit d'enquêtes de terrain menées en 2002. Depuis, ces données ont pu connaître des modifications, les rites new age étant caractérisés par leur labilité et leur instabilité.

25. Je remercie Juan Núñez del Prado pour sa collaboration et son aide. 
26. Hanaqpacha (le « monde du haut ») est une des composantes de la vision tripartite du monde andin. Les deux autres sont kaypacha (le « monde d'ici ») et ukhupacha (l'« inframonde »). En réalité, les Runa ne considèrent le plus souvent que les deux derniers niveaux.

27. Taytacha Temblores, Petit Père des Tremblements, est adoré spécialement le lundi de Pâques. Il est considéré dans les prières comme un dieu des montagnes (Valencia Espinoza 1991) et, en tant que tel, il peut même apparaître sur la table rituelle d'un chamane de haut rang.

28. Voir Flores Ochoa (1977), Ricard Lanata (2010). Ces croyances ont certainement une origine préhispanique comme le montre le dictionnaire de Gonzáles Holguín (1952 [1608], p. 366).

29. Voir http://tonebytone.com/hatunkarpay/0.shtml, consulté le 11/05/2012. Pour le tourisme mystique au Cuzco, se reporter à Flores Ochoa (1996).

30. Lieu cérémoniel important situé au centre du Cuzco incaïque (Zuidema 1964).

\section{RÉFÉRENCES CITÉES}

Altamirano José

1993 Saqsaywaman : síntesis de la cultura andina (interpretación mística), Región Inka/Proyecto Especial Regional Parque Arqueológico Saqsaywaman, Cusco (Qosqo).

Arguedas José María

1968 Los mitos quechuas posthispániscos, Casa de las Américas, La Havane.

BAUER Brian

$1998 \quad$ The sacred landscape of the Inca. The Cusco ceque system, University of Texas Press, Austin.

BERTONIO Ludovico

1984 Vocabulario de la lengua aymara, CERES/IFEA/MUSEF, Cochabamba [1612].

BouysSe-CASSAGNe Thérèse

$1987 \quad L a$ identidad aymara. Aproximación histórica (siglo XV, siglo XVI), HISBOL/IFEA, La Paz.

BouysSE-CASSAGNE Thérèse et Olivia Harris

1987 "Pacha : en torno al pensamiento aymara », in Thérèse Bouysse-Cassagne, Olivia Harris, Verónica Cereceda et Tristan Platt, Tres reflexiones sobre el pensamiento andino, Hisbol, La Paz, pp. 11-61.

Burga Manuel

1988 Nacimiento de una utopía : muerte y resurección de los incas, Instituto de Apoyo Agrario, Lima.

Сово Bernabé

1964 "Historia del Nuevo Mundo », in Obras del P. Bernabé Cobo, Ediciones Atlas, coll. «Biblioteca de Autores Españoles » 92, Madrid, tome 2, lib. XI-XIV, pp. 8-275 [1653].

Cumes Carol et Rómulo LizÁrRaga VALENCIA

1999 Pachamama's children, Llewellyn Publications, St Paul.

DousseT Laurent

1999 «Le New Age movement. Une étude préliminaire » [manuscrit]. 
ESTENSSORo Juan Carlos

1992 «Modernismo, estética, música y fiesta : élites y cambio de actitud frente a la cultura popular. Perú, 1750-1850 », in Henrique Urbano (éd.) Tradición $y$ modernidad en los Andes, Centro de estudios regionales andinos «Bartolomé de las Casas », Cuzco.

FERGuSOn Marylin

1981 Les Enfants du Verseau, Calmann-Lévy, Paris.

Flores GALINDo Alberto

1986 Buscando un Inca. Identidad y utopía en los Andes, Casa de las Américas, La Havane.

FLORES OCHOA Jorge

1977 "Enqa, enqaychu, illay khuya rumi », in Jorge Flores Ochoa (éd.), Pastores de puna. Uywamichiq punarunakuna, Instituto de Estudios Peruanos, Lima, pp. 211-237.

1996 «Buscando los espíritus de los Andes : turismo místico en el Qosqo », in Hiroyasu Tomoeda et Luis Millones (éd.), La tradición andina en tiempos modernos, National Museum of Ethnology, coll. «Senri Ethnological Reports » 5, pp. 9-29.

Flores OChOA Jorge et Juan Victor NúÑEZ del Prado (éd.)

1984 Q'ero, el último ayllu inka. Homenaje a Oscar Núñez del Prado, Centro de estudios andinos Cuzco, Cuzco.

GALINIER Jacques et Antoinette MoLInIÉ

2006 Les néo-Indiens. Une religion du III millénaire, Odile Jacob, Paris.

Garcilaso de la Vega Inca

1960 Obras completas, 4 vols, Ediciones Atlas, coll. «Biblioteca de Autores Españoles », Madrid [1609].

GonZÁlez Holguín Diego

1952 Vocabulario de la lengua general de todo el Peru llamada lengua quichua o del Inca, Instituto de Historia, Lima [1609].

Guaman Poma de Ayala Felipe

1980 El primer Nueva corónica y buen gobierno, édité par John Murra, Rolena Adorno et Jorge Urioste, Siglo Veintiuno, Mexico [1615].

Hobsbawm Eric et Terence RANGer (éd.)

1983 The invention of tradition, Cambridge University Press, Cambridge.

ITIER César

1997 Parlons quechua. La langue du Cuzco, L'Harmattan, Paris.

2009 «Una percepción folclorizada y arcaizante del quechuas : el diccionario quechua-español-quecha de la Academia Mayor de la Lengua Quechua », in Valérie Robin Azevedo et Carmen Salazar-Soler (éd.), El regreso de lo indígena. Retos, problemas y perspectivas, Lima, Institut français d'études andines/ Centro de estudios regionales andinos « Bartolomé de las Casas », pp. 265-285. 
JenKINS Elizabeth B.

1997 Il ritorno dell'Inka, Sonzogno, Milan.

Le Cour Paul

1986 L'ère du verseau, Dervy-Livres, Paris [1937].

Le Blanc de Guillet Antoine

1782 Premier Ynca du Pérou, Belin, Paris.

LONGATO Renato

1991 «Perú centro magnético », Gnosis. Revista de esoterismo iniciático, 5, pp. 21-30.

Mariátegui José Carlos

$1928 \quad$ Siete ensayos de interpretación de la realidad peruana, Amauta, Lima.

MARMONTEL Jean-François

1895 Les Incas ou la destruction de l'empire du Pérou, Librairie de la bibliothèque nationale, Paris [1777].

Molina « el Cuzqueño » Cristóbal de

1916 «Relación de las fábulas y ritos de los incas », in Horacio Urteaga et Carlos Romero (éd.), Colección de libros y documentos referentes a la historia del Perú, Imprenta y Librería Sanmartí, Lima, 1e série, tome 1, pp. 1-103[1575].

Molinié Antoinette

1979 «Cure magique dans la vallée sacrée du Cuzco », Journal de la Société des Américanistes, 66, pp. 85-98.

1996 «Las tres madres del Perú. Cuzco en las representaciones de la identidad nacional peruana », Crónicas urbanas, 5, pp. 79-84, Cuzco.

2004 "The resurrection of the Inca : the role of Indian representations in the invention of the nation », History and Anthropology, 15 (3), pp. 233-250.

2009 «Del inca nacional a la Internacional inca », in Valérie Robin Azevedo et Carmen Salazar-Soler (éd.), El regreso de lo indigena. Retos, problemas y perspectivas, Institut français d'études andines/Centro de estudios regionales andinos « Bartolomé de las Casas », Lima, pp. 237-264.

NúÑEZ Del Prado Juan Victor

1991 «El sacerdocio andino actual», in Mariusz S. Ziółkowski (éd.), El culto estatal del imperio inca, CESLA, Varsovie, pp. 127-137.

1998 Camminando nel cosmo vivente. Guide alle tecniche energetiche e spirituali delle Ande, Macro edizioni, Cesena.

NúÑEZ Del Prado Oscar

1973 «Versión del mito de Inkarrí en Q’eros », in Juan Ossio (éd.), Ideología mesiánica del mundo andino, Ed. Ignacio Prado Pastor, Lima, pp. 275-280.

O'PHelan Godoy Scarlett

1995 La gran rebelión de los Andes : de Tupac Amaru a Tupac Catari, Centro de estudios regionales andinos « Bartolomé de las Casas », coll. « Archivos de Historia Andina » 20, Lima/Cuzco.

Ortiz ResCaniere Alejandro

1973 De Adaneva a Inkarrí, Ed. Retablo de papel, Lima. 
Ossio Juan (éd.)

1973 Ideología mesiánica del mundo andino, Ed. Ignacio Prado Pastor, Lima.

Pachacuti YamQi Joan de Santa Cruz

1950 "Relaciones de antigüedades deste Reyno del Piru », in Marcos Jiménez de la Espada (éd.), Tres relaciones, Ed. Guaraní, Asunción, pp. 207-281 [1613].

PARISI WiLcox, Joan et Elizabeth B. Jenkins

1996 «Journey to Q'ollorit'i : initiation into the Andean mysticism », Shaman's Drum, 40, pp. 34-49.

Pilares Villa Rubén

1992 Turismo místico. Parodia o trascendencia, Ed. Ayar, Cuzco.

Platt Tristan

1978 "Symétries en miroir. Le concept de yanantin chez les Macha de Bolivie », Annales ESC, 5-6, pp. 1081-1107.

Ricard Lanata Xavier

2010 Les voleurs d'ombre. L'univers religieux des bergers de l'Ausangate (Andes centrales), Société d'ethnologie, Nanterre.

Sivirichi Atilio

1946 Derecho indigena peruano, Ed. Kuntur, Lima.

Sullivan William

1999 El secreto de los incas, Ed. Grijalbo, Barcelona.

TAMAYo Herrera José

$1980 \quad$ Historia del indigenismo cuzqueño, siglo $X V I-X X$, Instituto Nacional de la Cultura, Lima.

URIEL García José

1973 El Nuevo Indio, Ed. Universo, Lima [1930].

VALCÁRCEL Luis

1927 Tempestad en los Andes, Biblioteca Amauta, Lima.

VALDERRAMa Ricardo et Carmen Escalante

1995 «El Inka vive», Revista del Museo e Instituto de Arqueología, 25, pp. 241-270, Cuzco.

Valencia EsPinoza Abraham

1991 Taytacha temblores, patrón jurado del Cuzco, Centro de estudios regionales andinos « Bartolomé de las Casas », Cuzco.

VERNETTE Jean

1992 Le New Age, Presses universitaires de France, coll. «Que sais-je ? » 2674, Paris.

ZUIDEMA Tom $\mathrm{R}$.

1964 The Ceque system of Cuzco. The social organization of the capital of the Inca, E. J. Brill, Leiden.

1986 La civilisation inca de Cuzco, Presses universitaires de France, Paris.

2010 El calendario inca. Tiempo y espacio en la organización ritual del Cuzco. La idea del pasado, Fondo editorial del congreso del Perú/Fondo editorial de la Pontificia Universidad Católica del Perú, Lima. 